\title{
EUROPEIZACJA TOP-DOWN W KULTURZE JAKO EFEKT POLITYKI KULTURALNEJ UE
}

\author{
Abstract \\ TOP-DOW EUROPEANISATION IN CULTURE AS THE EFFECT OF THE UE \\ CULTURAL POLICY
}

The aim of this article is to analyse how Europeanisation top-down process affects the EU cultural policy. Europeanisation, as an academic concept in political sciences and European studies, became popular if not fashionable in other disciplines during the last two decades, creating new perspectives of scientific discourse. In the case of cultural policy of the UE it influences mechanism of integration in cultural sector as well as process of identification with European community's values, axiological standards and beliefs. It is also affecting management areas, project management especially, as well as leadership, standardisation, democratisation of political decisions, and methods of administrative governance of the European cities. All those instruments used in Europeanisation processes might help in deeper integration between European nations and make people's Europe far more aware of a need to participate in cultural transition in Europe.

SŁOWA KLUCZE: polityka kulturalna Unii Europejskiej, europeizacja w politykach kulturalnych, dialog wielokulturowy, pomocniczość

KEY WORDS: the EU cultural policy, europeanisation in cultural policies, multicultural dialogue, subsidiarity

Europeizacja jest nową kategorią badawczą w nauce o polityce oraz w studiach europeistycznych. Zalicza się ją do subdyscypliny europeistyki. Nie jest teorią europeistyczną, raczej metodą wyjaśniającą procesy integracyjne. W tym celu europeizacja posługuje się narzędziami innych dziedzin: wykorzystuje teorie stosunków międzynarodowych, klasyczne teorie integracji europejskiej, teorię komunikacyjną, funkcjonalizm, neofunkcjonalizm, realizm, liberalizm, uniwersalne teorie nauk społecznych (w tym nowy instytucjonalizm), wykorzystuje też narzędzia politologiczne (teorię demokracji, legitymację władzy, systemy polityczne). Istnieje około ośmiu 
teorii europeizacji proponowanych przez badaczy różnych dziedzin. Aby móc użyć kategorii europeizacji w rozważaniach o kulturze w kontekście procesów integracyjnych, należy wyjaśnić znaczenie pojęcia oraz wskazać główne źródła bibliograficzne.

Politolodzy i europeiści zgadzają się, że europeizacja to proces dostosowywania państw członkowskich Unii Europejskiej do wymogów aguis communautaire, czyli implementacja prawa i polityk UE na poziomie wewnątrzkrajowym ${ }^{1}$. Podkreślają, że europeizacja nie jest synonimem uwspólnotowienia. Uznają również, że europeizacja to proces, a nie stan, oraz że to proces nielinearny i niejednorodny. Najczęściej wskazują na jej dwutorowy charakter. Dwutorowość opisywali w szczególności niemieccy badacze: Tanja A. Börzel i Thomas Risse w publikacji When Europe hits home: Europeanisation and domestic change w $2000 \mathrm{roku}^{2}$. Analizowali oni dwutorowość jako proces odgórny (top-down), kiedy instytucje ponadnarodowe oddziałują na państwa narodowe, a te otwierają się na to oddziaływanie, oraz jako proces oddolny (bottom-up), czyli odbywający się poprzez transfer kompetencji z poziomu krajowego na poziom ponadnarodowy. Idąc tym tropem, należy stwierdzić, że europeizacja umożliwia otwarcie się instytucji państwa narodowego na wpływy instytucji ponadnarodowych (supranarodowych), tym samym przyjęcie transferu zasad, przepisów i standardów europejskich na poziom krajowy z poziomu europejskiego. Jednocześnie - europeizacja to kształtowanie przepisów ponadnarodowych na podstawie dziedzictwa prawnego suwerennych państw. To, która z tych płaszczyzn przeważa, zależy najczęściej od formuły i charakteru danej polityki. Bywa, że dwutorowość jest rozłożona równomiernie, jednakże w większości przypadków europeizacja oznacza proces adaptacji przepisów krajowych do rozwiązań ponadnarodowych. Można powiedzieć, że europeizacja top-down ma wymiar formalny, a europeizacja botoom-up mniej formalny. Istnieje też europeizacja horyzontalna cross-loading, która następuje wtedy, kiedy zachodzi transfer procedur wynikający z wzajemnej komunikacji i wymiany.

Najbardziej klasyczne definicje europeizacji reprezentują rozważania brytyjskich badaczy, Helen Wallace oraz Roberta Ladrecha; amerykańskiego politologa Jamesa Caporaso oraz Claudio Radaelliego, profesora Uniwersytetu z Exeter (pochodzenia włoskiego). Helen Wallace jako jedna z pierwszych dostrzegała możliwość

${ }^{1}$ Pisze o tym wielu badaczy, m.in. T.A. Börzel, Europeanization: How the European Union Interacts with its Member States [w:] S. Bulmer, Ch. Lequesne (red.), The Member States of the European Union, New York 2005, s. 45-76; T.A. Börzel, T. Risse, Europeanization: The Domestic Impact of EU Politics [w:] K.E. Jørgensen, M.A. Pollack, B.J. Rosamond (red.), The Sage Handbook of European Union Politics, London 2007, s. 483-504; M.G. Cowles, J. Caporaso, T. Risse, Trasforming Europe and Domestic Change, Ithaca 2002; J.P. Olsen, Many faces of Europeanisation, ,Journal of Common Market Studies” 2002, No. 40 (5).

2 T.A. Börzel, T. Risse, When Europe hits home: Europeanisation and domestic change, „European Integration" 2000, No. 4 (15) online paper, oraz w artykule: Conceptualizing the Domestic Impact of Europe [w:] E. Featherstone, C.M. Radaelli (red.), The Politics of Europeanisation, Oxford 2003. Szczegóły tego procesu są opisane również w publikacji: P. Buras, K. Pomorska, Europeizacja - nowe podejście analityczne $w$ studiach nad polityka zagraniczna, ,Stosunki Międzynarodowe" 2008, nr 3-4, s. 31-49. 
wpływu procesów integracyjnych na wewnątrzpaństwowe relacje międzyinstytucjonalne ${ }^{3}$, ale podkreślała różność tego wpływu w zależności od tradycji prawnopolitycznych danego państwa. Badania nad europeizacją rozpropagował Robert Ladrech, który w roku 1994 uznał, że zjawisko europeizacji w integracji to ,postępujący proces przeformułowania kierunków i kształtu polityki, w wyniku którego polityki i gospodarcza dynamika Wspólnoty staje się elementem logiki organizacyjnej narodowej polityki i polityk”4. W późniejszych tekstach Ladrech ${ }^{5}$ podkreślał szczególnie ,adaptację krajową" w procesach integracyjnych, która oznaczała, że w trakcie przyjmowania prawnych wytycznych wspólnotowych dochodzi do reorientacji treści polityk krajowych, co w dalszej kolejności oznacza, iż działania realizowane na poziomie ponadnarodowym czy supranarodowym stają się naturalną częścią składową wewnętrznych polityk kraju członkowskiego. James Caporaso ${ }^{6}$ stworzył cytowany wielokrotnie w literaturze przedmiotu model mechanizmu europeizacji, polegający na zjawisku sprzężenia zwrotnego. Trafnie zjawisko to, jak i europeizacyjny model Caporaso, zinterpretował Rafał Riedel:

Prowadziło to badaczy europeizacji do przyjęcia definicji - uznawanej już dziś za klasyczną pozwalającej widzieć europeizację jako postępujący proces integracji europejskiej, który wywołuje swego rodzaju presję na podmioty integracji (państwa członkowskie, ich obywateli, instytucje), podlegającą następnie mediacji za pośrednictwem czynników i aktorów wewnątrzkrajowych, a następnie przynosi konkretne efekty w postaci zmian w polityce wewnętrznej. Rezultaty te (jak również etap mediacji) poprzez mechanizm sprzężenia zwrotnego wpływają również na proces integracji ${ }^{7}$.

Riedel ilustruje powyższy proces schematem: integracja - mediacja (sprzężenie zwrotne) - rezultat. Według Caporaso istotą europeizacji są zatem: odpowiedź na presję wywieraną przez siły ponadnarodowe na siły wewnątrzkrajowe oraz konkretna zmiana wewnątrzkrajowa wynikająca z tej presji, ale tworzona poprzez mediację. Zmiana wywołana mediacją wpływa na integrację przez sprzężenie zwrotne. Można powiedzieć nieco tautologicznie, że zmiana ,zmienia” proces integracji. Ważny jest również fakt, że proces zakłada aktywność (nie pasywność) podmiotu, wobec którego wywierana jest presja. Jego włączanie się w proces europeizacji zachodzi poprzez wielopoziomową mediację (którą Caporaso nazywa sprzężeniem zwrotnym),

${ }^{3} \mathrm{H}$. Wallace, The Impact of the European Communities on national policy-making, ,,Government and Opposition" 1971, No. 4 (6).

${ }^{4}$ R. Ladrech, Europeanisation of domestic politics and institutions: the case of France, ,Journal of Common Market Studies” 1994, No. 32(1), s. 69.

${ }^{5}$ R. Ladrech, Europeanisation and national politics, London, 2010, oraz także: T. Poguntke, N. Aylott, R. Ladrech, K.R. Luther, The Europeanisation of national party organisations: A conceptual analysis, „European Journal of Political Research” 2007, No. 46 (6), s. 747-771.

${ }^{6}$ J. Caporoso, Three words of regional integration theory [w:] P. Graziano, M.P. Vink (red.), Europeanisation. New Research Agendas, London 2007.

7 R. Riedel, Europeizacja polityk publicznych, „Wrocławskie Studia Politologiczne” 2015, nr 18, s. 58. 
czyli negocjacje, dyskusję, polemikę ${ }^{8}$. Claudio Radaelli w swoim tekście Europeanisation in Public Policy ${ }^{9}$ wymienia cztery sposoby przystosowania państwa członkowskiego do procesów integracyjnych. Należą do nich: 1. Redukcja lub kontestacja (dany obszar polityczny występuje przeciwko regulacjom wspólnotowym). 2. Inercja (brak woli dostosowania się, brak zmiany, marazm, bierny opór). 3. Akomodacja lub absorpcja (powierzchowne przystosowanie struktur, jednostek i państwa do wymogów integracji). 4. Transformacja (przekształcanie się struktur, jednostek i państwa na poziomie wewnątrzkrajowym, głęboka zmiana dostosowawcza). Cztery wymienione płaszczyzny stwarzają inne możliwości adaptacyjne, co świadczy o tym, że europeizacja na różnym etapie procesów integracyjnych może przebiegać różnie. Może przybrać odmienne też formy w zależności od typu polityk publicznych oraz czasu jej zastosowania. Może się okazać, że w przypadku procesów dostosowawczych z zakresu ochrony środowiska nastąpi tymczasowa redukcja, a potem transformacja; w przypadku polityki regionalnej głęboka transformacja bezpośrednia, a w przypadku polityki audiowizualnej - akomodacja.

Według brytyjskiego badacza Kevina Featherstone'a ${ }^{10}$ termin europeizacja posiada cztery rejestry znaczeniowe. Pierwszy to, podobnie jak u innych analityków, proces instytucjonalnego dostosowania krajów członkowskich UE do zobowiązań wynikających z przynależności do ponadnarodowych europejskich struktur, m.in. w zakresie administracji publicznej, działalności parlamentu i partii politycznych, społeczeństwa obywatelskiego, samorządu terytorialnego itd., a także do formalnych regulacji UE. Stopień drugi to adaptacja polityk i sposobu uprawiania polityki. Dwa kolejne obszary cechuje wymiar antropologiczno-historyczny. Obszar trzeci generuje więc pytania o identyfikację kulturową i poczucie przynależności do odpowiedniego miejsca i czasu w procesie historycznym. Czwarty poziom europeizacji tworzy warunki do dyfuzji ponadnarodowych wzorów i norm kulturowych (w tym aksjologii europejskiej, praw człowieka, wartości demokratycznych). Pewną odmianę do definicji europeizacji wprowadzili badacze skandynawscy, a zwłaszcza Johan P. Olsen w słynnym eseju Many faces of Europeanisation $(2002)^{11}$. Olsen dostrzega pięć poziomów europeizacji, z których najważniejszy tworzy się w wyniku „scentralizowanej (odgórnej) penetracji narodowych systemów rządzenia"12. Pozostałe to zmiany generowane pod wpływem impulsów zewnętrznych (UE), rozwoju instytucji na poziomie europejskim i wynikającej z niego coraz większej zdolności do rządzenia UE; również eksport logiki integracyjnej wewnątrz UE i poza granice UE.

8 James Caporaso powtórzył opisany model europeizacji również w książce: M. Cowles Green, J. Caporaso, T. Risse (red.), Transforming Europe. Europeanisation and Domestic Change, Ithaca 2001.

9 C. Radaelli, The Europeanization of Public Policy [w:] K. Featherstone, C. Radaelli (red.), The Politics of..., s. 27-56.

${ }^{10}$ F. Featherstone, C. Radaelli (red.), The Politics of...

11 J.P. Olsen, Many faces of...

12 Tamże, s. 923-924. 
Można chwilowo podsumować. Pojęcie europeizacji ma wymiar głównie polityczny, redukujący dyskurs o wartościach czy normach, czemu akurat bliska jest kultura. Jest pojęciem w pewnym sensie wykluczającym, gdyż - jak trafnie spostrzega Marta Lackowska-Madurowicz - dyskurs o wartościach „nie implikuje ograniczenia pojęcia do struktur unijnych"13. Wyznacza szersze horyzonty. Z tego punktu widzenia rozważania o kulturze w kontekście europeizacji stają się kłopotliwe. Dlatego zachowujemy tok dyskursu politologicznego, lokując zagadnienia związane z kulturą w obszarze tzw. miękkich polityk UE, aby tym samym dokonać analizy europeizacji kultury z punktu widzenia politycznych procesów integracyjnych. Koncentrujemy się na analizie mechanizmu europeizacyjnego top-down. Sprawdzamy, jak impulsy integracyjne, zdefiniowane jako cele programów kulturalnych UE, wpływają na transformację kulturową w Polsce. Przyjmujemy założenie, że w przypadku polskiej kultury mamy do czynienia z konkretnymi zmianami instytucjonalnymi, czyli „odbiciem" tendencji integracyjnych. Wskazują na to wypowiedzi operatorów kulturalnych i uczestników europejskich programów kulturalnych.

Dziedzina kultury należy do najsłabszych obszarów interwencji formalnoprawnej UE. Ilościowe zestawienie aktów prawnych, które podlegały implementacji z poziomu europejskiego na poziom krajowy w odpowiednich dziedzinach, wskazuje na fakt (co podaje Rafał Riedel ${ }^{14}$ ), że kultura lokuje się na podobnej pozycji jak edukacja, nauka oraz informacja. Liczba przyjętych aktów prawnych (razem w tych dziedzinach: 559) jest znikoma w porównaniu z polityką rolną (32 797), polityką konkurencji (6766) czy wspólną polityką zagraniczną i bezpieczeństwa (1344). Riedel w związku z tym twierdzi, że kultura, podobnie jak edukacja jest „obszarem prawie wolnym od europeizacji” ${ }^{15} \mathrm{w}$ sensie obligatoryjności implementacji prawa wspólnotowego. Kultura należy więc do europejskich polityk miękkich (słabych) ${ }^{16}$, na co pośrednio wskazuje Grzegorz Tomasz Grosse:

Należy przypomnieć, że europeizacja bazuje również na „miękkich” i zdecentralizowanych sposobach oddziaływania, takich jak demonstrowanie najlepszych praktyk, niezobowiązujących prawnie wytycznych i rekomendacjach. Duże znaczenie mają procesy socjalizacji w instytucjach europejskich, które sprzyjają koncyliacji i zachęcają do wdrażania norm europejskich. Europeizacja tworzy zestaw idei i wartości politycznych sprzyjających integracji europejskiej.

${ }^{13}$ M. Lackowska-Madurowicz, Europeizacja - ramy koncepcyjne dla badań samorzadów?, „Zarządzanie Publiczne” 2011, nr 1 (15), s. 40.

${ }_{14}$ R. Riedel, Europeizacja polityk..., s. 56-72.

15 Tamże, s. 69.

16 Pojęcie polityki „miękkiej” czy „niskiej” wzięło początek od analiz harwardzkiego badacza Josepha Nye. Badacz przeciwstawił pojęciu hard power określenie soft power w analizach finansowych. W Unii Europejskiej przyjęło się określenie „miękkie prawo”, czyli soft law, kiedy mowa o instrumentach nieposiadających mocy wiążącej, czyli o komunikatach, rekomendacjach, opiniach (a nie dyrektywach czy decyzjach). Instrumenty prawa miękkiego określają w pewnym sensie miękką politykę UE, czyli taką politykę, w której Komisja wykonuje swoje zadania nie w formule obligatoryjnej, ale w ramach traktatowej swobody działania. Więcej na ten temat w: R.O. Keohane, J.S. Nye, Power and. Interdependence: World Politics in Transition, Boston 1977; D.M. Craig, „High Politics” and the „New Political History”, ,,The Historical Journal” 2010, No. 53, s. 453-475. 
Jej skuteczność oddziaływania zależy w dużym stopniu od woli politycznej w państwach członkowskich, a ta jest kształtowana także pod wpływem „miękkich” i nieformalnych mechanizmów oddziaływania. W tym kontekście można zauważyć, że „miękkie” formy europeizacji mają uzupełniać, a w pewnym stopniu nawet maskować braki systemu instytucjonalnego ${ }^{17}$.

A także:

Wśród „miękkich” instrumentów prawnych znajdują się europejskie strategie, komunikaty i wytyczne oraz wszystkie nieformalne mechanizmy oddziaływania, np. interpretacje przepisów europejskich stosowane przez decydentów unijnych, negocjacje międzyrządowe lub międzyinstytucjonalne w Unii Europejskiej itp. Przykładem „miękkiej” metody zarządzania jest tzw. otwarta metoda koordynacji ${ }^{18}$.

Kultura, będąc przypisana do polityk słabych (soft power), posiada swoje wytyczne formalne. Są nimi przepisy traktatowe, wprowadzające fundamentalny dla kultury w UE paradygmat ,jedności w różnorodności” (art. 128 Traktatu o WE w wersji z Maastricht, art. 151 WE w wersji traktatu Amsterdamskiego i Nicejskiego oraz art. 167 TFUE). Istnieją też przepisy wykonawcze typu Decyzje. Regulacje traktatowe obligują UE do stwarzania warunków do współpracy i wymiany pomiędzy operatorami kulturalnymi w Europie. Najistotniejszym przepisem, warunkującym procesy europeizacyjne w kulturze, są pkt 1 i pkt 2 art. 167 TFUE, które formułują cele polityki kulturalnej UE

- pkt 1:

Kultura przyczynia się do rozkwitu kultur państw członkowskich w poszanowaniu ich różnorodności narodowej i regionalnej, równocześnie podkreślając znaczenie wspólnego dziedzictwa kulturowego.

- pkt 2:

Działanie Wspólnoty zmierza do zachęcania do współpracy między Państwami Członkowskimi oraz, jeśli to niezbędne, do wspierania i uzupełniania ich działań w następujących dziedzinach: pogłębiania wiedzy oraz upowszechniania kultury i historii narodów europejskich; zachowania i ochrony dziedzictwa kulturowego o znaczeniu europejskim; niehandlowej wymiany kulturalnej; twórczości artystycznej i literackiej włącznie z sektorem audiowizualnym ${ }^{19}$.

${ }_{17}$ G.T. Grosse, Europeizacja jako mechanizm władzy: przykład funkcjonowania strefy euro, http://ur.edu.pl/pliki/Zeszyt19/01.pdf, s. 23-24 [odczyt: 5.08.2017].

18 Otwarta Metoda Koordynacji (OMK) to międzyrządowy mechanizm polityczno-regulacyjny, którego celem jest samoobserwacja państw w danej dziedzinie i przekazywanie sobie dobrych praktyk, które jednocześnie są monitorowane na poziomie Rady Europejskiej, wzmacniając zarazem ten organ. To system polegający na dobrowolnym udziale państw w pracy na rzecz danego sektora z udziałem również organizacji pozarządowych i wyspecjalizowanych grup eksperckich. Celem nadrzędnym zastosowania Otwartej Metody Koordynacji jest osiągnięcie efektu spójności w systemie pryncypiów i zarządczości sferą kultury w EU.

19 Traktat z Lizbony, zmieniający traktat o Unii Europejskiej, i traktat ustanawiający Wspólnotę Europejską, podpisany w Lizbonie 13 grudnia 2007 r. (teksty skonsolidowane), Dz.U. UE z dnia 7.06.2016, C 202, s. 121-122. 
Unii przypisano w traktacie działania „zachęcające”, ,pobudzające”, ,uzupełniające" w stosunku do działań kulturalnych państw członkowskich. W związku z tym UE nie posiada w zakresie kultury kompetencji wyłącznej (pozwalającej na zastosowanie metody interwencjonistycznej). Posiada kompetencję wspierającą, którą przypieczętowuje art. 5 TFUE, wprowadzający zasadę pomocniczości, mówiącą, iż Unia podejmuje działania tylko wówczas i tylko w takim zakresie, w jakim ,cele zamierzonego działania nie mogą zostać osiągnięte w sposób wystarczający przez Państwa Członkowskie, zarówno na poziomie centralnym, jak i regionalnym oraz lokalnym i jeśli ze względu na rozmiary i skutki proponowanego działania możliwe jest lepsze ich osiągnięcie na poziomie Unii”. Zastosowanie wobec kultury zasady pomocniczości chroni narodowe polityki kulturalne. Komisja Europejska pełni funkcję komplementarną wobec krajowych polityk kulturalnych i jedyne, co może robić, to zachęcać państwa członkowskie do uczestnictwa w ofercie kulturalnej przygotowanej na szczeblu wspólnotowym, którą cechuje wymiar europejski. W praktyce wszystkie kraje UE biorą udział w oferowanych przez UE programach kulturalnych, które są tworzone w warunkach wieloletnich negocjacji z reprezentantami krajów członkowskich. Fakt, że negocjacje te odbywają się na szczeblu międzyrządowym, skutkuje słabą identyfikacją lokalnych i regionalnych instytucji kultury z tym procesem. Można powiedzieć, że formalnie proces europeizowania kultury dotyczy w państwie członkowskim jedynie poziomu centralnego. Programy oferowane przez UE są promowane w krajach członkowskich poprzez Punkty Kontaktowe ds. Kultury oraz metodą centralnej organizacji konkursu na Europejską Stolicę Kultury (ESK). Na szczeblu unijnym Komisja ogłasza unijne konkursy tematyczne, do których nominacje mogą zgłaszać zarówno instytucje, sieci, organizacje, jak i osoby prywatne z całej Europy. Wszystkie wymienione wyżej działania odbywają się za obopólną zgodą i akceptacją dla formuły organizacyjnej oraz instytucjonalnej proponowanej przez UE. Udział instytucji kulturalnych w programach UE, za których wdrożenie odpowiedzialne jest państwo, ma charakter dobrowolny. Państwa członkowskie, zgadzając się na oferowanie na swoim terytorium programów UE, wypełniają postanowienia traktatowe, w tym zasadę pomocniczości. Powyższy proces implementacyjny jest przykładem europeizacji top-down w zakresie kultury. Zachodzi on wobec wszystkich państw członkowskich Unii. Jego celem jest generalnie efektywność przekazu impulsu integracyjnego z poziomu unijnego na poziom krajowy, natomiast w kulturze - wprowadzenie europejskich priorytetów integracji kulturalnej do praktyki projektowej, czyli na poziom konkretnych wydarzeń artystyczno-kulturalnych (koncerty, wystawy, przedstawienia) przygotowanych przez instytucje kultury, organizacje pozarządowe, wydawnictwa itp.

Wielu badaczy twierdzi, że zasada pomocniczości pozbawia Unię Europejską instrumentów władzy, marginalizując jej rolę w kulturalnych aspektach integracji europejskiej, oraz że de facto nie jest ona zasadą o charakterze normatywnym ${ }^{20}$. Inni uważają, że ponieważ Unia nie ukształtowała w procesie integracji ustroju federalnego,

20 Z. Sokolewicz, Polityka kulturalna Wspólnot Europejskich i Rady Europy a zasada subsydiarności [w:] D. Milczarek (red.), Subsydiarność, Warszawa 1998, s. 187-199, oraz H. Klebes, Subsydiarność w pracach Rady Europy oraz jej relacjach z Unią Europejską [w:] Subsydiarność, 
suwerenność państw członkowskich odgrywa zasadniczą rolę, choć spowalnia integrację i przyczynia się do chronicznych kryzysów Wspólnoty ${ }^{21}$. Jeszcze inni są zdania, że pozwala na niezależność w relacjach UE - państwa członkowskie. Wyznacza równowagę relacji politycznych ${ }^{22}$. Sama Komisja Europejska jeszcze w roku 1992, czyli przed wprowadzeniem Traktatu z Maastricht, podkreślała, że ,subsydiarność nie może być wykorzystywana do ubezwłasnowolnienia Komisji z powodu zagrożenia jej prawa do podejmowania inicjatywy legislacyjnej i tym samym zachwiania równowagi uprawnień ustanowionej przez traktaty"23. Niezależnie od stanowisk poglądowych możemy z całą pewnością powiedzieć, że Unia Europejska zachowuje dalece idącą delikatność, jeśli chodzi o uprawnienia w zakresie kultury. Szanuje konstytucyjne i legislacyjne zadania państw w tym względzie. Można nawet powiedzieć, że „hamuje” czy spowalnia europeizację top-down.

Zasada pomocniczości jest zaimplementowana do wszystkich programów kulturalnych oferowanych przez UE (np. w programach ostatniej i obecnej dekady: „Kultura 2000”, „Kultura 2007-2013”, „Kreatywna Europa”), co oznacza, że występuje w decyzjach o ich powołaniu. Zasadę pomocniczości zastosowano w pkt 18 Decyzji z 1999 roku, pkt 30 Decyzji z 2006 oraz pkt 36 Decyzji z roku 2013, powołujące się na art. 5 TFUE. W pkt 18 Decyzji z 1999 roku Komisja otwarcie przyznaje, że nie wychodzi poza wymagane minimum, podkreślając poszanowanie dla polityk kulturalnych krajów członkowskich będących podstawą polityki kulturalnej UE. Pkt 30 Decyzji z 2006 roku podkreśla komplementarność działań UE wobec działań krajowych. Pkt 36 Decyzji z 2013 roku potwierdza logikę subsydiarności, dodając szersze zadania unijne, wynikające z połączenia działań na rzecz kultury z działaniami na rzecz przemysłów kreatywnych. Powstaje pytanie, co Unia Europejska traktuje jako możliwe do osiągnięcia na poziomie wspólnotowym i co jest powodem uruchamiania działań komplementarnych? Czyli w imię jakich priorytetów włączane są procesy europeizacyjne top-down? Jan Truszczyński, jeden z czołowych polskich negocjatorów w procesie zjednoczeniowym, odpowiada na pytanie w następujący sposób:

Oczywiście, główna odpowiedzialność za kulturę spoczywa na państwach członkowskich, ale od włączenia kultury do Traktatu z Maastricht w 1992 roku coraz baczniej zdawano sobie sprawę, że unijne wsparcie dla kultury może przynieść dodatkowe korzyści dzięki możliwości podjęcia wyzwań, z którymi państwa członkowskie mogłyby poradzić sobie równe efektywnie, gdyby działały oddzielnie. Tak naprawdę wiele wyzwań stojących dziś przed europejskimi sektorami działalności kulturalnej i twórczej dotyczy problemów ponadnarodowych. Są one związane z zawrotnym tempem, w jakim zmiany technologiczne idą do przodu w skali

s. 53-60, a także W. Szpringer, Subsydiarność jako zasada ustrojowa w państwie federalnym-członku Unii Europejskiej (na przykładzie RFN) [w:] Subsydiarność, s. 101-115.

${ }^{21}$ Report on cultural cooperation in the European Union (2000/2323(INI)) Committee on Culture, Youth, Education, the Media and Sport. Rapporteur: Giorgio Ruffolo. European Pariament, 16.06.2001, FINAL A5-0281/2001.

${ }^{22}$ K. Głąbicka, Polityka społeczna Wspólnot Europejskich, Warszawa 1998, s. 51.

${ }^{23}$ Communication of Commission to the Council and the European Parliament, Europe Documents, 20.10.1992, Brussels, s. 98. Cyt. za: D. Milczarek (red.), Subsydiarnośćc, wyd. 2, Warszawa 1998 , s. 320. 
globalnej i koniecznością nadążania za tymi zmianami przez rozwinięcie umiejętności, jakich wymaga działalność na poziomie międzynarodowym. To właśnie tu działania UE mogą zapewnić wyraźną wartość dodaną ${ }^{24}$.

Należy zatem wzmocnić wspólnotę regionalną dla zadań globalnych. Ten cel wyłania się z głównych założeń programowych. Celem programu „Kultura 2000” i tym samym praktycznego zastosowania idei europeizacji była m.in.:

[...] promocja twórczości i ponadnarodowego upowszechniania kultury oraz przemieszczania się artystów, twórców, innych działaczy kultury i profesjonalistów oraz ich prac, ze szczególnym naciskiem na młodych i społecznie pokrzywdzonych oraz na różnorodność kulturową; [...] rozwój nowych form ekspresji kulturalnej; dzielenie i podkreślanie, na poziomie europejskim, wspólnego dziedzictwa kulturowego o znaczeniu europejskim; upowszechnianie wiedzy i promowanie dobrych praktyk dotyczących ochrony i zabezpieczania tego dziedzictwa; uwzględnianie roli kultury w rozwoju społeczno-gospodarczym; poprawa dostępu do uczestnictwa kulturalnego w Unii Europejskiej dla możliwie największej liczby obywateli ${ }^{25}$.

Niektóre z wymienionych zadań programu „Kultura 2000” dublują cele polityk krajowych. Inne jednak posiadają wyłącznie europejską dominantę. Wyznaczają cele ponadnarodowe, służące łączeniu Europejczyków, a nie ich dzieleniu, eksplorowaniu wspólnego dziedzictwa przy poszanowaniu zróżnicowania kulturowego ludzi i narodów Europy. Właśnie w procesie poszukiwania rdzenia kulturowego, podobieństw i wspólnych doświadczeń, odkrywania wspólnej pamięci, niechcianej przeszłości, tkwi idea integracji. Zatem europeizacja w polityce kulturalnej UE jest rozumiana jako „podróż ku wspólnocie”, a nie czysto formalne dostosowywanie regulacji prawnych. Cele programu „Kultura 2007-2013” tylko w niewielkim stopniu modyfikowały priorytety swojego poprzednika. Podkreślano explicite, że dbanie o kulturę w UE służy celom integracyjnym, a na tym etapie procesów, czyli od roku 2007, przechodzi w fazę wzmocnienia społeczeństwa obywatelskiego. Jako nowy aspekt działań Komisja podkreśliła w programie wsparcie dla kultur mniejszych oraz mniej używanych języków europejskich, a także rolę czynników ekonomicznych w działalności kulturalnej oraz ich wpływu na innowacyjność zarówno sztuki, jak i gospodarki. Program zakładał m.in. takie cele, jak:

[...] promocję dialogu kulturalnego i wzajemnego poznawania kultury i historii narodów europejskich; promocję twórczości i ponadnarodowego upowszechniania kultury oraz przemieszczania się artystów, twórców, innych działaczy kultury i profesjonalistów oraz ich prac; podkreślanie różnorodności kulturowej i rozwój nowych form ekspresji kulturalnej; upowszechnianie wiedzy i promowanie dobrych praktyk dotyczących ochrony i zabezpieczania dziedzictwa; uwzględnianie roli kultury w rozwoju społeczno-gospodarczym; wyraźne uznanie kultury jako czynnika ekonomicznego oraz jako czynnika w społecznej integracji i budowaniu poczucia obywatelstwa ${ }^{26}$.

${ }^{24}$ Program Kultura oczami Komisji Europejskiej. Wywiad z Janem Truszczyńskim [w:] Kulturalna Unia Europejska, Program Kultura pod lupa, Warszawa 2011, s. 46.

${ }_{25}$ Decyzja nr 508/2000/WE Parlamentu Europejskiego i Rady z dnia 14 lutego 2000 r. ustanawiająca program „Kultura 2000”, Dz.Urz. UE L 63/1 z dnia 10.03.2000 r, s. 98-99.

26 Tamże, s. 98-99. 
Art. 2 Decyzji stwierdzał dodatkowo, że cele zostają osiągnięte trzema metodami: poprzez wspieranie innowacyjności i działań eksperymentalnych; poprzez zintegrowane wieloletnie działania, służące tworzeniu partnerstw i sieci instytucji kulturalnych oraz kształtowanie wydarzeń międzynarodowych o charakterze europejskim. Pomoc UE miała zostać skierowana głównie do instytucji działających w partnerstwie lub zrzeszonych w sieciach.

Podobne założenia reprezentowały decyzje PE i Rady dotyczące funkcjonowania Europejskiej Stolicy Kultury. Decyzja 1622/2006 wprowadzała w art. 4 konkretne kryteria, które musiały obligatoryjnie zostać wdrożone do programu ESK: 1. W odniesieniu do „Wymiaru europejskiego” celem programu jest: a) wzmocnienie współpracy w każdym sektorze kultury między operatorami w dziedzinie kultury, artystami i miastami z danego państwa członkowskiego i innych państw członkowskich; b) podkreślenie bogactwa różnorodności kulturowej w Europie; c) uwypuklenie wspólnych aspektów kultury europejskiej; 2. W odniesieniu do „Miasta i obywateli” celem programu jest: a) wspieranie udziału mieszkańców danego miasta i jego okolic oraz zwiększenie zainteresowania miastem z ich strony oraz ze strony obywateli mieszkających za granicą; b) trwałość i stanowienie integralnej części długofalowego rozwoju kulturalnego i społecznego miasta ${ }^{27}$. Zwróćmy jeszcze uwagę na charakterystyczne „europejskie” cele Nagród Unii Europejskiej. Coroczna Nagroda Literacka Unii Europejskiej, ustanowiona w roku 2008, ma za zadanie promowanie ponadnarodowej mobilności ludzi kultury, zachęcanie do transgranicznej cyrkulacji efektów pracy artystycznej i kulturalnej oraz wspomaganie dialogu międzykulturowego ${ }^{28}$. Nagroda imienia Miesa van der Rohe dla architektury europejskiej, przyznawana co dwa lata, jest rezultatem współpracy UE z Fundacją im. Miesa van der Rohe z Barcelo$n y^{29}$. Organizatorzy tak wyjaśniają sens wyróżniania europejskich architektów:

Sektor architektury jest jednym z podstawowych filarów branży kultury oraz branży twórczej w Europie. Jest w nim zatrudnionych bezpośrednio ponad pół miliona osób, a ponad 12 milionów pracuje w przemyśle budowlanym. Jako część branży kultury i branży twórczej architektura jest źródłem 4,5\% PKB Unii Europejskiej"”30 [...] podkreśla ona wkład europejskich architektów w rozwój nowych rozwiązań i technologii we współczesnym środowisku miejskim ${ }^{31}$.

Sumując wymienione przez Unię cele, można dostrzec rozbieżność w stosunku do partykularnych celów narodowych polityk kulturalnych. We wszystkich cytowanych przykładach pojawia się zwielokrotniona liczba mnoga, koncept europejskiej zbiorowości, konstruowany $\mathrm{z}$ niezależnych zbiorowości narodowych. Kluczowa jest idea dialogu kultur, komunikacji międzykulturowej i metajęzykowej, zrozumienie różnorodności kultur europejskich jako aksjomatu budowania tożsamości

${ }^{27}$ Decyzja nr 1622/2006/WE Parlamentu Europejskiego i Rady z dnia 24 października 2006 r. ustanawiająca działanie Wspólnoty na rzecz obchodów „Europejskiej Stolicy Kultury” w latach 2007-2019, Dz.Urz. UE L304/1, 3.11. 2006, s. 2-3.

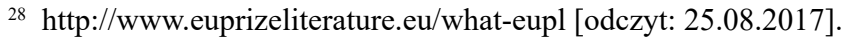

${ }^{29}$ Fundacja przyznawała tę nagrodę od 1987 r., wraz z UE przyznaje od 1991.

${ }^{30}$ esben.com/wp-content/uploads/2015/05/2015-05-08-PL.pdf [odczyt: 15.07.2017].

31 Tamże. 
i obywatelstwa. Istotna jest również znajomość europejskiej literatury pięknej, historii narodów europejskich, wzrost gospodarczy oraz rozwój miejskich metropolii. Można uznać, że na poziomie zadań Unia dąży do wzmocnienia kultur europejskich jako obszaru żywotnych interesów państw członkowskich. Ważnym priorytetem jest ustanowienie trwałej płaszczyzny współpracy międzyinstytucjonalnej w celu tworzenia silnych i konkurencyjnych ośrodków zarządzania, promowania wspólnych osiągnięć artystycznych (w tym architektonicznych) na zewnątrz Europy, a także wzajemnego inspirowania się artystów. Wymienione cele polityki kulturalnej UE można potraktować jako instrument procesów europeizacyjnych. Europeizacja top-down jest zmianą, która dokonuje się w wyniku realizacji polityki kulturalnej. Europeizacja to również wpływanie na zmiany miejskie, aby dochodziło do transformacji miast: $\mathrm{z}$ centrów europeizmu (w sensie funkcjonowania aktywnych środowisk intelektualnych i biznesowych, sprzyjających idei otwarcia, tolerancji i partycypacji) w ośrodki kształtujące nowoczesne społeczeństwa miejskie, świadome swojej roli w rozwoju gospodarczym i technologicznym europolis.

Warto zastanowić się nad pytaniem, jak mechanizmy europeizacyjne odbierane są przez osoby biorące udział w programach wspólnotowych i widzą one rolę swoich instytucji i swoich projektów w procesie adaptacyjnym. Wielu beneficjentów podkreśla wagę pryncypiów europejskiej polityki kulturalnej, wyrażonej w dokumentach unijnych i implementowanej do programów. Zauważają możliwość realizacji tych założeń w praktyce, jak np. Ewa Majczak, działaczka Culture Action Europe (europejska platforma na rzecz rozwoju kultury i sztuk):

Kultura, dziedzictwo kulturowe i sztuka ilustrują naszą kulturową różnorodność. Otwierają fizyczną i mentalną przestrzeń dla indywidualnej i zbiorowej wyobraźni, stanowiąc narzędzie pomagające nam w lepszym rozumieniu międzykulturowej rzeczywistości. Te kulturowe wymiary muszą być lepiej uwzględnione w przyszłych politykach, również dlatego, że zgodnie z ostatnimi statystykami, ponad 90\% Europejczyków uważa, że kultura powinna ogrywać istotną rolę $e^{32}$.

Operatorzy kulturalni sprzyjają zwłaszcza idei dialogu międzykulturowego. Tak było w przypadku oceny programu „Kultura 2007-2013” przez beneficjentki projektu „Międzynarodowa Parada Smoków: mity i legendy Europy”:

Ten rodzaj międzynarodowej konfrontacji uświadomił nam również, że do innej kultury tak naprawdę nie jesteśmy w stanie dotrzeć w pełni z przekazem na temat własnej kultury. Możliwa jest wymiana i konfrontacja, z których rzeczywiście powstaje inspiracja i namiastka dialogu ${ }^{33}$.

Inni zauważają, że realizacja projektów europejskich, w tym Europejskiej Stolicy Kultury 2016, pozwala na odkrycie zasobów miasta i regionu. W procesie aplikacji

${ }^{32}$ Działaj na rzecz kultury w Europie! Kampania We Are More. Wywiad z Ewą Majczak, Kulturalna Unia Europejska. Program Kultura pod lupa. IAM, Punkt Kontaktowy ds. Kultury, Warszawa 2011, s. 75.

${ }^{33}$ Program Kultura oczami beneficjenta. Wywiad z Olgą Lany i Joanną Zając, Kulturalna Unia Europejska. Program..., s. 29. 
do ESK dochodziło, według uczestników polskiego konkursu ${ }^{34}$, do pogłębionej refleksji nad tym:

Dla mnie coś, co jest bardzo lokalne czy regionalne, jest równocześnie wyznacznikiem europejskości. Śląsk ma kulturę lokalna, którą pielęgnuje, która od setek lat jest silnie w ludziach zakorzeniona $^{35}$.

Wielu uczestników konkursu ESK w Polsce uważa, że przygotowywanie aplikacji konkursowych na rok 2016 było procesem poważnych zmian świadomości: „...taki proces ogólnej europeizacji mentalnej i urbanistycznej, gdyż Europa zmierza obecnie w kierunku takiego ekologicznego zarządzania miastami"36. Pozytywnie o współpracy na poziomie europejskim wypowiadają się reprezentanci środowisk literackich. Europeizacja to dla nich mechanizm promocji polskiej literatury w Europie oraz wprowadzanie na polski rynek autorów mało poczytnych i niszowych:

Program „Kultura” w moim odczuciu jest idealnym rozwiązaniem dla wydawców, którzy chcą promować nieznanych w Polsce autorów i wydawać ich dzieła. Bez tego wsparcia wydanie niektórych pozycji mogłoby w najlepszym wypadku opóźnić się, a inne tytuły nie zostałyby w ogóle opublikowane. Co niezwykle istotne. Program zachęca do tłumaczenia dzieł napisanych w językach mniej popularnych, jak choćby islandzki ${ }^{37}$.

Oraz:

Promocja kultury, w tym przypadku poprzez literaturę, to podstawowy cel zarówno Programu, jak i samych wydawców ${ }^{38}$.

Polska literatura, dzięki wyspecjalizowanym instytutom oraz możliwościom uczestnictwa w obiegu europejskim na większą skalę, była ostatnimi laty doskonale odbierana na międzynarodowych targach książek w Europie i na świecie. W kraju wzrosła liczba wydawnictw oraz agencji literackich i tłumaczeniowych ${ }^{39}$.

Zjawisko europeizacji polskiej kultury to - jak twierdzą uczestnicy programów oraz badacze $U^{40}$ - kwestia nabywania umiejętności menedżerskich. To sztuka

${ }^{34}$ Dane na temat polskiego konkursu ESK 2016 w publikacji: P. Kubicki, B. Gierat-Bieroń, J. Orzechowska-Wacławska, Efekt ESK. Jak konkurs nad Europejska Stolicę Kultury zmienit polskie miasta, Kraków 2017.

${ }^{35}$ P. Kubicki, B. Gierat-Bieroń, J. Orzechowska-Wacławska, Efekt ESK..., s. 226.

36 Tamże, s. 225.

${ }^{37}$ Program Kultura oczami beneficjenta. Wywiad z Sebastianem Florjanowiczem, Kulturalna Unia Europejska. Program..., s. 39.

${ }^{38}$ Tamże.

${ }^{39}$ Rynek książki w Polsce, Instytut Książki, http://www.instytutksiazki.pl/upload/Files/polish book_market_2015_PL_popr.pdf [odczyt: 6.08.2017] oraz Stan czytelnictwa w Polsce w 2016, Biblioteka Narodowa, Warszawa 2016, http://www.bn.org.pl/download/document/1493378303.pdf [odczyt: 8.08.2017].

40 Wiele tego typu twierdzeń znajdziemy w monografiach: Danuty Glondys, Kazimierza Walucha, Jacka Purchli; w opracowaniach Joanny Sanetry-Szeligi i Agaty Etmanowicz oraz artykułach Doroty Jurkiewicz-Eckert. 
zarządzania międzynarodowymi projektami i dużymi funduszami, przekazanymi z UE (również z funduszy strukturalnych). Podkreślane jest zdobywanie kompetencji ekonomicznych oraz kształtowanie pozycji lidera w Europie:

Wbrew opiniom sceptyków sektor kultury okazał się jednym z najlepiej przygotowanych do absorpcji środków europejskich. Dzisiaj z pełną odpowiedzialnością mogę powiedzieć, że jesteśmy liderem ich wykorzystania. Świadczą o tym zakończone z sukcesem projekty, które cieszą się ogromnym zainteresowaniem zwiedzających i publiczności. Centrum Nauki Kopernik, które było jedną z pierwszych oddanych do użytku inwestycji w ciągu 2,5 roku funkcjonowania odwiedziło 2,5 mln gości ${ }^{41}$.

Polacy szybko uczą się kompetencji zarządczych poprzez programy unijne, czego dowodzi wypowiedź jednego z działaczy łódzkich uczestniczących w tworzeniu aplikacji konkursowej ESK na rok 2016:

[...] mamy już tutaj menedżerów kultury, którzy są już w sieci międzynarodowej, to była nowa kategoria, wcześniej takiej nie było - menedżer kultury, to są ludzie, którzy mają kontakty, wiedzą, jak się ludzi sprowadza, pozyskują środki, mają taki rodzaj wiedzy, jakiego brakuje dyrektorom instytucji kultury, którzy czekają na dotację celową ${ }^{42}$.

Operatorzy kulturalni posługują się pojęciem standaryzacji usług i handlu jako dowodem na europeizowanie polskich instytucji kultury poprzez konkurs na ESK:

[...] wydaje mi się, że sam fakt kandydatury podwyższył pewne standardy - np. w galeriach pojawiły się materiały anglojęzyczne, oferta dla zagranicznego turysty, projekty międzynarodowe i rezydencje ${ }^{43}$.

W przypadku „Kultury 2007-2013” dało się zauważyć poczucie satysfakcji $\mathrm{z}$ uczestnictwa $\mathrm{w}$ tak dużym logistycznie programie ${ }^{44}$. Partycypacja $\mathrm{w}$ programach wspólnotowych to sposób na budowanie prestiżu zespołu artystycznego i utrzymanie się w nurcie europejskim. Ważne są kwestie wizerunkowe. Instytucje, które raz znalazły się na europejskiej mapie, pragną na niej pozostać. Nie chcą powrotu na margines. Obserwatorzy życia teatralnego w Polsce twierdzą ${ }^{45}$, że instytucje te zaczęły brać udział w wielopoziomowej strukturze organizacyjnej (poprzez sieci instytucjonalne, koprodukcje) oraz weszły w procesy kosmopolityzacji. Stały się otwarte na nowości ze względu na bezpośrednie kontakty międzyinstytucjonalne, mają dostęp do zagranicznej wiedzy eksperckiej. Zatem ważnym rezultatem procesów europeizacyjnych top-down w Polsce jest umiędzynarodowienie instytucji kulturalnych.

${ }^{41}$ M. Smoleń, Stowo wstępne [w:] Nowa przestrzeń dla kultury. Program Operacyjny Infrastruktura i Środowisko 2007-2013, Warszawa 2013, s. 9.

42 P. Kubicki, B. Gierat-Bieroń, J. Orzechowska-Wacławska, Efekt ESK, s. 227.

43 Tamże, s. 229.

${ }^{44}$ Program Kultura 2007-2013 w Polsce. Analiza i podsumowanie, Punkt Kontaktowy ds. kultury, IAM, Warszawa 2013.

${ }^{45}$ www.nck.pl/blog-kultura-sie-liczy/316789-decentralizacja-a-europeizacja-przypadek-polskich-teatrow/ [odczyt:10.08.2017]. 
Operatorzy kulturalni przedstawiają ciekawie samą ideę europejskiego miasta w kontekście konkursu na ESK w Polsce. Współczesne europejskie miasto widzą jako ekologiczne, budowane z myślą o ludziach: „...zielone, przyjazne, otwarte, ten Rynek, który tętni życiem - to daje poczucie energii" ${ }^{46}$ (mowa o Wrocławiu). To również idea miasta rządzonego metodami demokratycznymi, w którym decyzje zapadają w sposób transparentny. Oczekiwanie demokratyzowania decyzji rad miejskich wynika z widocznych już zmian w prowadzeniu lokalnych polityk kulturalnych oraz działalności administracji publicznej, która - jak zauważa Robert Grzeszczak - podlega europeizacji:

Jest to wpływ o charakterze wertykalnym i dotyczy dwóch wymiarów - po pierwsze, zmian w strukturze administracji krajowej, a po drugie, efektów, jakie dla krajowego prawa administracyjnego ma uwzględnianie prawa unijnego. Jest to także oddziaływanie horyzontalne, bardziej dostrzegalne w punktu widzenia jednostki, polegające na zmianie funkcjonowania administracji krajowej, jej usprawnieniu, zmianie standardów itp. ${ }^{47}$.

Sceptycy procesów europeizacyjnych w kulturze podkreślają niedostateczne przygotowanie instytucji kultury do partycypacji w programach europejskich. Powody? Bariery mentalne, słaba znajomość języków obcych, brak międzynarodowego doświadczenia ${ }^{48}$. To uznają za źródło niepowodzeń, czyli przeciętnej obecności polskich instytucji w programach UE, czego dowodzą statystyki ${ }^{49}$, i tym samym

${ }^{46}$ P. Kubicki, B. Gierat-Bieroń, J. Orzechowska-Wacławska, Efekt ESK..., s. 226.

${ }^{47}$ R. Grzeszczak, Proces europeizacji administracji krajowej na przykładzie modelu koordynacji spraw europejskich w Polsce, ,Rocznik Administracji Publicznej” 2016, nr 2, s. 274, http: // www.ejournals.eu/RAP/ISSN 2449-7800 [odczyt: 10.08.2017].

${ }^{48}$ Brak doświadczenia i odpowiedniej wiedzy eksperckiej widać na przykładzie Łodzi. Tamtejsze środowisko dziennikarskie negatywnie postrzega metody europeizacyjne miasta, wprowadzane przez lokalny samorząd. Europeizacja w tym konkretnym przypadku do próba adaptowania do miejskiej polityki kulturalnej niefunkcjonalnej idei „miasta kreatywnego” Richarda Floridy, która zrobiła zawrotną karierę w poprzedniej dekadzie w Europie, a dziś uchodzi za nietrafioną. Nie jest to idea unijna, jednakże niezwykle popularna jako trend kulturowy, wspomagający rozwój miast. Florida przyznał, że skutkiem narodzin klasy kreatywnej jest powstawanie miast rządzonych przez ludzi zamożnych, co sprzyja marginalizacji ubogich, generuje procesy wykluczenia, separację i rodzi podziały. Ponadto, aby udało się stworzyć nową narrację miasta, nie można kultywować tradycyjnych metod rządzenia. A tak postrzegana jest Łódź, co podkreśla Igor Rakowski-Kłos, cytując Floridę: ,przeklejanie niekompleksowo pojętych mechanizmów z innych ośrodków miejskich i rozwiązań bez uwzględnienia lokalnej specyfiki nigdy nie zadziała”. I. Rakowski-Kłos, Kreatywna Łódź to pomyłka. Miliony poszły w błoto?, „Gazeta Wyborcza”, Łódź, 9 października 2015, odz. wyborcza.pl/lodz/1,35153,18994251,kreatywna-lodz-to-pomylka-miliony-poszly-w-bloto-opinia. html [odczyt: 4.07.2017].

${ }^{49}$ Najlepiej pokazuje to podsumowanie cząstkowe programu Kultura 2007-2013: Interim Evaluation of the Culture Programme 2007-2013, ECORYS 2010, w którym widać, że polscy operatorzy, unikając pozycji lidera projektów, zdecydowanie częściej współpracują na zasadzie partnerstwa. Również Joanna Sanetra-Szeliga w swoim komentarzu do oceny programu Kultura 2007-2013 stwierdzała, że niekwestionowanym liderem europejskich projektów w kulturze są Włochy (Program Kultura 2007-2013 - analiza i podsumowanie, Punkt Kontaktowy ds. Kultury, IAM, Warszawa 2013). 
powolnej ich europeizacji. Próby współpracy na poziomie międzynarodowym traktują jak tradycyjną wymianę bilateralną. Walka o ekonomiczne status quo polskich instytucji kulturalnych nie pozwala na myślenie w kategoriach dialogu międzykulturowego czy mobilności artystów. Beneficjenci rozumieją, że programy UE są nastawione na kształtowanie mechanizmów współpracy, ale te mechanizmy w Polsce są ciągle słabe. Jako szczególnie negatywne oceniają zjawisko „projektyzacji”, czyli postrzegania współpracy na poziomie UE w kategoriach opanowania sztuki pisania wniosków aplikacyjnych i zrobienia $\mathrm{z}$ tego sposobu na zarabianie pieniędzy, czyli utrwalania status quo.

Ponieważ, jak wspomnieliśmy, proces europeizacji w kulturze nie jest wynikiem twardej polityki kulturalnej UE, a przebiega swobodnie, to można przyjąć, że wspomaga wolnościowy klimat kultury i potrzebę niezależności artystów. Opiera się na stopniowym - jak chciał Ladrech - „przeformułowaniu kierunków” i form działań instytucji. Prowokuje refleksję nad współczesną funkcją miast, lokalną i regionalną polityką kulturalną, budzi potrzeby współpracy międzynarodowej oraz apetyty na nowoczesne, funkcjonalne obiekty kultury. Powoduje reorientacje decyzji, ale też inspiruje artystów do poszukiwania nowatorskich metod twórczych. Będąc jednym $\mathrm{z}$ wielu paralelnie przebiegających procesów kształtowania krajowego życia artystycznego, odznacza się tym, że wzmaga i utrwala europejski system norm i technik działania. W wyniku realizacji wielopoziomowej współpracy europejskiej dochodzi do procesów dyfuzji idei i wartości, zgodnie z poglądem, że

[...] europeizacja zakłada powstanie pewnych wewnętrznych norm europejskich, które są zdolne kształtować negocjacje aktorów państwowych. Normy te mogą spowodować, że aktorzy nie tylko dokonują określonych wyborów, ale internalizacja pewnych idei (wartości, norm) stopniowo przebudowuje interesy nawet silnych aktorów ${ }^{50}$.

Kwestią niezwykle ważną jest zatem fakt narodzin postaw proeuropejskich, wykształcanie pewnych układów normatywnych, opartych na podobnym rozumieniu demokracji, partnerstwa, solidarności i zaufania, które mają znaczący wpływ na politykę instytucjonalną, personalną czy projektową, ale również profilowanie postaw akceptacji dla procesów zjednoczeniowych. To odkrywanie i docenianie wspólnoty wartości i zasad wydaje się najbardziej znaczącym rezultatem europeizacji top-dow w kulturze. Synergię potrzeb i aspiracji artystów europejskich podkreślał już parę lat temu Dragan Klaić, były ekspert ds. programów międzynarodowych UE, teatrolog, wykładowca Uniwersytetu w Lejdzie:

Wszyscy działający w Europie, czy to w państwach członkowskich Unii Europejskiej, czy poza nimi, muszą rozumieć proces integracji europejskiej, znać instytucje unijne, kompetencje w dziedzinie kultury określone w artykule 151 Traktatu Ustanawiającego Wspólnotę Europejską, a także oparte na tym zapisie programy. Działalność na arenie międzynarodowej oznacza, że wcześniejszych doświadczeń, krajowego systemu kultury i najczęściej stosowanych

${ }^{50}$ P. Rieker, From Common Defence to Comprehensive Security Towards the Europeanisation of French Foreign and Security Policy, Norwegian Institute of Foreign Affairs 2005, No. 691. Cyt. za: T. Młynarski, Między interesem narodowym a wspólnotowym..., s. 430. 
metod pracy nie można stosować jako jedynego czy obowiązkowego układu odniesienia; trzeba uwzględniać, analizować i porównywać odniesienia, wyznaczniki i sygnały pochodzące z szerszej przestrzeni kultury w Europie ${ }^{51}$.

\section{Bibliografia}

Bache I., Europeanization and Multilevel Governance. Cohesion Policy in the European Union and Britain, Lanham-Boulder-New York-Toronto-Plymouth UK 2008.

Bauer M.W., Knill Ch., Pitschel D., Differential Europeanization In Eastern Europe: The Impact of Diverse EU Regulatory Governance Patterns, „Journal of European Integration” 2007, Vol. 29, No. 4, s. 405-423.

Burgoński P., Europeizacja polskiej polityki równościowej i antydyskryminacyjnej, „Przegląd Europejski” 2012, nr 2 (25), s. 145-167.

Börzel T.A., Panke D., Introduction: what is Europeanization? [w:] M. Cini, N. Pérez-Solórzano Borragán (red.), European Union Politics, Oxford-New York 2010, s. 406-417.

Börzel T.A., Europeanization: How the European Union Interacts with its Member States [w:] S. Bulmer, Ch. Lequesne (red.), The Member States of the European Union, New York 2005, s. 45-76.

Börzel T.A., Risse T., Europeanization: The Domestic Impact of EU Politics [w:] K.E. Jørgensen, M.A. Pollack, B.J. Rosamond (red.), Handbook of European Union Politics, London 2007, s. $483-504$.

Börzel T.A., Risse T., When Europe hits home: Europeanisation and domestic change, „European Integration" 2000, No. 4 (15) online paper.

Börzel T.A., Conceptualizing the Domestic Impact of Europe [w:] E. Featherstone, C.M. Radaelli (red.), The Politics of Europeanisation, Oxford 2003, s. 1-23.

Bulmer S., Theorizing Europeanization [w:] P. Graziano, V. Vink (red.), Europeanization: New Research Agendas, Basingstoke 2007, s. 46-58.

Buras P., Pomorska K., Europeizacja - nowe podejście analityczne w studiach nad polityka zagraniczna, ,Stosunki Międzynarodowe” 2008, nr 3-4, s. 31-49.

Cowles M.G., Caporaso J., Risse T., Transforming Europe and Domestic Change, Ithaca 2002.

Caporoso J., Three words of regional integration theory [w:] P. Graziano, M.P. Vink (red.), Europeanisation. New Research Agendas, Basingstoke 2007.

Craig D.M., ,High Politics” and the „New Political History”, „The Historical Journal” 2010, No. 53, s. 453-475.

Featherstone K., Introduction: In the name of Europe [w:] K. Featherstone, C.M. Radaelli (red.), The Politics of Europeanization, Oxford 2003, s. 3-26.

Featherstone K., C. Radaelli (red.), The Politics of Europeanization, Oxford 2003, s. 27-56.

Głąbicka K., Polityka społeczna Wspólnot Europejskich, Warszawa 1998.

Grosse G.T., Systemowe spojrzenie na europeizacje, „Studia Europejskie” 2012, nr 3, s. 9-27.

Grosse G.T., W objęciach europeizacji, Warszawa 2012.

Grosse G.T., Europeizacja jako mechanizm władzy: przykład funkcjonowania strefy euro, http:// ur.edu.pl/pliki/Zeszyt19/01.pdf [odczyt: 15.08.2017].

Grosse T.G., Europeizacja administracji. Nowe metody zarzadzania w nowych państwach członkowskich Unii Europejskiej [w:] L. Kolarska-Bobińska (red.), Nowe metody zarzadzania w państwach Unii Europejskiej, Warszawa 2009, s. 101-131.

${ }^{51}$ D. Klaić, Mobilność wyobraźni. Międzynarodowa wspótpraca kulturalna. Przewodnik, Warszawa 2011, s. 108. 
Grzeszczak R., Proces europeizacji administracji krajowej na przykładzie modelu koordynacji spraw europejskich w Polsce, „Rocznik Administracji Publicznej” 2016, nr 2, s. 272-290, http://www.ejournals.eu/RAP/ISSN 2449-7800 [odczyt: 10.08.2017].

Heywood A., Politologia, Warszawa 2009.

Hooghe L., Marks G., Multi-level Governance and European Integration, Lanham 2009.

Keohane R.O., Nye J.S., Power and. Interdependence: World Politics in Transition, Boston 1977.

Klaić D., Mobilność wyobraźni. Międzynarodowa wspótpraca kulturalna. Przewodnik, Warszawa 2011.

Klebes H., Subsydiarność w pracach Rady Europy oraz jej relacjach z Uniq Europejska [w:] D. Milczarek (red.), Subsydiarność, Warszawa 1998, s. 53-60.

Kubicki P., Gierat-Bieroń B., Orzechowska-Wacławska J., Efekt ESK. Jak konkurs nad Europejska Stolice Kultury zmienit polskie miasta, Kraków 2017.

Kulturalna Unia Europejska. Program Kultura pod lupa, Warszawa 2011.

Lackowska-Madurowicz M., Europeizacja - ramy koncepcyjne dla badań samorzadów?, „Zarządzanie Publiczne" 2011, nr 1 (15), s. 39-57.

Ladrech R., Europeanization of Domestic Politics and Institutions: The Case of France, ,Journal of Common Market Studies" 1994, No. 1, Vol. 32, s. 69-88.

Ladrech R., Europeanisation and national politics, London 2010.

Młynarski T., Między interesem narodowym a wspólnotowym. Europeizacja polityki na przykładzie sektora energetycznego, http://ptsm.edu.pl/wp-content/uploads/publikacje/poziomy-analizy-stosunkow-miedzynarodowych/Mlynarski.pdf [odczyt: 5.06.2017].

Nowa przestrzeń dla kultury. Program Operacyjny Infrastruktura i Środowisko 2007-2013, Warszawa 2013.

Olsen J.P., The many faces of Europeanization, „Journal of Common Market Studies” 2002, No. 5, Vol. 40, s. 921-952.

Poguntke T., Aylott N., Ladrech R., Luther K.R., The Europeanisation of national party organisations: A conceptual analysis, „European Journal of Political Research” 2007, No. 46 (6), s. $747-771$.

Radaelli C., The Europeanization of Public Policy [w:] K. Featherstone, C.M. Radaelli (red.), The Politics of Europeanization, Oxford 2003, s. 27-56.

Rakowski-Kłos I., Kreatywna Łódź to pomyłka. Miliony poszły w błoto?, „Gazeta Wyborcza”, Łódź, 9 października 2015, odz.wyborcza.pl/lodz/1,35153,18994251,kreatywna-lodz-to-pomylka-miliony-poszly-w-bloto-opinia.html [odczyt: 4.07.2017].

Riedel R., Europeizacja polityk publicznych, „Wrocławskie Studia Politologiczne” 2015, nr 18, s. $56-72$.

Rieker P., From Common Defence to Comprehensive Security Towards the Europeanisation of French Foreign and Security Policy, Norwegian Institute of Foreign Affairs 2005, No. 691.

Sokolewicz Z., Polityka kulturalna Wspólnot Europejskich i Rady Europy a zasada subsydiarności [w:] D. Milczarek, Subsydiarność, Warszawa 1998, s. 187-199.

Szpringer W., Subsydiarność jako zasada ustrojowa w państwie federalnym - członku Unii Europejskiej (na przykładzie RFN) [w:] D. Milczarek (red.), Subsydiarność, Warszawa 1998, s. $101-115$.

Tomaszewski W., Riedel R., Europeizacja w wymiarze tożsamościowym [w:] A. Pacześniak, R. Riedel (red.), Europeizacja: mechanizmy, wymiary, efekty, Torun-Wrocław 2014.

Wallace H., Europeanization and Globalization: Complementary or Contradictory Trends, „New Political Economy" 2000, No. 3, Vol. 5, s. 369-382.

Wallace H., The Impact of the European Communities on national policy-making [w:] „Government and Opposition" 1971, No. 4 (6), s. 520-538.

Wallace H., National Governments and the European Communities, PEP, European Series, No. 221, London 1973. 
Wach K., Wokót pojęcia europeizacji, „Horyzonty Polityki” 2010, nr 1 (1), s. 195-207.

Wach K., Wymiary europeizacji i jej kontekst, „Zeszyty Naukowe Uniwersytetu Ekonomicznego w Krakowie" 2011, nr 852, s. 29-43.

http://www.euprizeliterature.eu/what-eupl [odczyt: 25.08.2017].

esbcn.com/wp-content/uploads/2015/05/2015-05-08-PL.pdf [odczyt: 15.07.2017].

\section{Dokumenty UE:}

Communication of Commission to the Council and the European Parliament, Europe Documents, 20.10.1992, Brussels.

Decyzja 1419/1999/WE Parlamentu Europejskiego i Rady z dnia 25 maja 1999 r. ustanawiająca działanie Wspólnoty na rzecz obchodów „Europejskiej Stolicy Kultury” w latach 2005-2019. Dz.U. WE, L 166/1, 1.07.1999.

Decyzja nr 508/2000/WE Parlamentu Europejskiego i Rady z dnia 14 lutego 2000 r. ustanawiająca program „Kultura 2000”. Dz.Urz. UE, L 63/1 z dnia 10.03.2000.

Interim Evaluation of the Culture Programme 2007-2013, ECORYS 2010.

Report on cultural cooperation in the European Union (2000/2323(INI)) Committee on Culture, Youth, Education, the Media and Sport. Rapporteur: Giorgio Ruffolo. European Parliament, 16.06.2001, FINAL A5-0281/2001.

Decyzja nr 1855/2006/WE Parlamentu Europejskiego i Rady z dnia 12 grudnia 2006 r. ustanawiająca Program Kultura (2007-2013), Dz.Urz. UE, L372/1, 27.12.2006.

Decyzja nr 1622/2006/WE Parlamentu Europejskiego i Rady z dnia 24 października 2006 r. ustanawiająca działanie Wspólnoty na rzecz obchodów „Europejskiej Stolicy Kultury” w latach 2007-2019, Dz.Urz. UE L304/1, 3.11. 2006.

Traktat z Lizbony, zmieniający traktat o Unii Europejskiej i traktat ustanawiający Wspólnotę Europejską, podpisany w Lizbonie 13 grudnia 2007 r. (teksty skonsolidowane), Dz.Urz. UE z dnia 7.06.2016, C 202. 